\title{
EDITORIAL
}

\section{Caro Leitor:}

Este novo número de nossa Revista de Direito Sanitário está em absoluta consonância e total contemporaneidade com as grandes discussões teóricas e legais que estão definindo o Direito Sanitário do século XXI. Com efeito, há exatamente um ano atrás - no primeiro número do volume anterior de nossa Revista, publicado em março de 2002 - conversávamos neste espaço sobre o direito das políticas públicas, sobrevoando rapidamente os grandes traços que caracterizam esse direito. Concluímos, então, que a interpretação constitucional é uma exigência quando existe a possibilidade de interpenetração de diferentes áreas do conhecimento e a definição do campo de conhecimento que engloba tanto a ciência pura quanto a aplicada, característica da ciência hodierna. Pois bem, neste número o professor Dr. Germano Schwartz, da Universidade de Passo Fundo, no Rio Grande do Sul, nos traz a precisa lição do mestre Niklas Luhmann, que discutiu o sistema sanitário, concluindo que se trata, também, de um sistema autopoiético. Sem qualquer dúvida, trata-se de artigo instigante, que deve provocar a reação dos colegas de formação básica na área da saúde, especialmente pela valorização positiva da doença e, portanto, pela identificação do sistema sanitário com o sistema médico. Esse artigo deve estimular, também, os colegas que possuem formação básica na área jurídica, uma vez que apresenta o grande desafio posto ao Direito para trabalhar o Direito Sanitário: usar o velho para compreender o novo ou arriscar compreender o novo com o novo?

A atualidade de nossa Revista de Direito Sanitário pode ser comprovada, igualmente, pela publicação do artigo do professor Dr. Eric Mondielli sobre a evolução do direito da responsabilidade médica e hospitalar na França. De fato, essa análise foi provocada pela publicação da nova legislação, em março de 2002, que disciplinou o contencioso médico, unificando-o em torno de uma regra de direito comum à ordem administrativa e à ordem judiciária. O exame da atuação do Conselho de Estado e da Corte de Cassação, sempre no sentido da melhoria da reparação dos danos causados, permitiu concluir que a lei sobre "os direitos dos pacientes e qualidade do sistema de saúde" respeitou essencialmente o desenvolvimento jurisprudencial sem fundamentalmente questioná-lo. E se pôde, assim, contar com a preciosa e competente avaliação do nosso colega "nantais" dos pri- 
meiros resultados da legislação que introduz a "democracia sanitária" no sistema de saúde francês.

De inquestionável atualidade é, do mesmo modo, o tema em debate deste número da nossa Revista de Direito Sanitário: A Emenda Constitucional n. 29/2000 e o financiamento do sistema sanitário brasileiro. Nosso colega e colaborador, o advogado e mestre em Direito Fernando Aith acentua, com propriedade, a felicidade de contarmos com três excelentes artigos, de Ana Gabriela Filippi Sambiase, João Batista Lazzari e Marcelo Gouvêa Teixeira, que enfrentam as questões intrincadas e controversas que freqüentam as polêmicas discussões decorrentes dessa importante inovação Constitucional.

Este número da nossa Revista de Direito Sanitário conta, também, com o excelente artigo "O Município e a saúde: reflexões sobre as balizas impostas pelo ordenamento jurídico vigente para a atuação do poder público local", onde Claudia Aguiar de Siqueira, tomando como pano de fundo o contraste entre as competências executiva e legiferante analisa especificamente a vigilância sanitária e a saúde suplementar. Além disso, temos a satisfação de contar com a análise de um acórdão realizada pelos ex-alunos do Programa de Aprimoramento Profissional em Direito Sanitário e Advocacia em Saúde, desenvolvido pelo Centro de Estudos e Pesquisas de Direito Sanitário e o Núcleo de Pesquisas em Direito Sanitário da Universidade de São Paulo em conjunto com a Fundap (Fundação para o Desenvolvimento Administrativo do Estado de São Paulo), Candy Florêncio Thomé, Lílian Pereira da Silva e Marcelo Ribeiro dos Santos Bicudo, tratando da dispensa de empregado portador do HIV e com um competente estudo a respeito da posição do Superior Tribunal de Justiça sobre o direito à saúde, realizado pelo professor da Universidade de Campinas Dr. Luiz Cietto.

Estamos absolutamente convencidos de que as resenhas publicadas neste número da nossa Revista de Direito Sanitário apresentam duas obras de grande importância para os estudiosos do Direito Sanitário. Inicialmente foi analisada a obra "Direito à saúde: uma perspectiva constitucionalista", de autoria de Liton Lanes Pilau Sobrinho, um jovem e promissor talento na área, que realizou um estudo abrangente do tema, nos limites do novo Direito Constitucional. Em seguida pudemos contar com a análise competente da professora de Saúde Pública da Columbia University em New York, EUA e executiva do Fundo para População da Organização das Nações Unidas, Dra. Rosemary Barber-Madden, da obra de Erik Nord, "Cost-value analysis in health care: making sense out of QALYS", apresentando e discutindo os possíveis usos de um novo instrumento para a análise econômica em saúde.

Enfim, estamos seguros de estar apresentando uma valiosa contribuição para o desenvolvimento científico do Direito Sanitário, que tem sido possível graças à qualidade dos artigos e estudos recebidos. Entretanto, 
queremos insistir e encerrar nossa conversa repetindo o apelo feito no último número: "participem do processo de construção dessa verdadeira referência para o conhecimento em Direito Sanitário, enviando, além de artigos originais, sugestões para tema em debate e informações para a seção de jurisprudência e ementário, comentando um trabalho forense (sendo indispensável, nessa hipótese, a juntada da peça comentada), apresentando uma obra nacional ou estrangeira, fazendo ou não sua resenha. Igualmente, serão muito bem-vindas as sugestões de temas para debate e nomes de eventuais debatedores. Não deixe de contribuir! Desde já queremos agradecer sua colaboração para que a Revista de Direito Sanitário expresse o que de melhor se vem fazendo na busca da saúde como um direito de todas as pessoas. Muito Obrigada!" na busca da saúde como um direito de todas as pessoas. Muito Obrigada!

Sueli Gandolfi Dallari

Editora 